\title{
Invasive Canadian goldenrod (Solidago canadensis L.) as a preferred foraging habitat for spiders
}

\author{
Krzysztof Dudek $^{1}\left(\mathbb{D} \cdot\right.$ Michał Michlewicz $^{1} \cdot$ Monika Dudek $^{2} \cdot$ \\ Piotr Tryjanowski ${ }^{1}$
}

Received: 22 December 2015/Accepted: 14 July 2016/Published online: 29 July 2016

(c) The Author(s) 2016. This article is published with open access at Springerlink.com

\begin{abstract}
Invasions of alien species are a great threat to biodiversity and native species communities. There are many examples in the literature on how the invasive plants affect the natural environment. Beside reports on negative effects of these invasions, there are also several studies indicating a positive impact of the invaders. Canadian goldenrod (Solidago canadensis) is one of the most invasive plant species all over Europe. Earlier studies showed that the goldenrod affects natural plant communities and has a negative impact on many animals, both vertebrates and arthropods. However, all the studies were conducted during goldenrod flowering. In contrast, this study has tested the novel hypothesis that Canadian goldenrod has a positive effect on native spider hunting success and increases spider abundance in farmland outside the growing season. Observations were made during spring on 13 meadows: 7 invaded and 6 non-invaded by goldenrod. All tall plants from experimental plots $\left(1 \mathrm{~m}^{2}\right.$ each) were examined for the presence of spiders, their nets and prey. Prey items were counted only in spider webs. The results support the hypothesis that $S$. canadensis is a favourable foraging habitat for spiders: $14.6 \mathrm{spiders} / \mathrm{m}^{2}$ on invaded plots versus 2.2 on non-invaded ones. Many spiders of the families Theridiidae and Araneidae were found on
\end{abstract}

Handling Editor: Heikki Hokkanen.

Krzysztof Dudek

dudeekk@gmail.com

1 Department of Zoology, Institute of Zoology, Poznań University of Life Sciences, Wojska Polskiego 71 C, 60-625 Poznan, Poland

2 Laboratory of Neurobiology, Institute of Zoology, Poznań University of Life Sciences, Wojska Polskiego 71 C, 60-625 Poznan, Poland goldenrod plants, but on native plants only the Araneidae were found. Moreover, on invaded plots, much more prey items $/ \mathrm{m}^{2}$ were present in spiders webs than on non-invaded plots (155.3 vs. 13.8). The study is a rare example of a positive influence of invasive plants on the native arthropod community. This is also a novel approach that shows the importance of dry goldenrod stems in invaded ecosystems.

Keywords Invasive ecology $\cdot$ Alien species $\cdot$ Ecosystem services · Agriculture - Biological pest control · Biodiversity

\section{Introduction}

Invasions of alien plants are causes of serious problems, which affect biodiversity and native species communities (Fenesi et al. 2015a; Hejda et al. 2009; Schirmel et al. 2015, 2011; Skórka et al. 2010). Recent studies have shown that a majority of interactions between invasive plants and native animal species are unfavourable for the animals (56\% are negative and $44 \%$ neutral), especially for birds and insects (Schirmel et al. 2015). However, there are a small number of studies showing the positive effects of alien invasive plants on animals, mostly on arthropods. For example, nitrophilous grass Elymus athericus modifies natural habitats and increases the survival of spiders during flood (Pétillon et al. 2005, 2010), whereas Impatiens glandulifera provides services for pollinators (Chittka and Schürkens 2001). Nevertheless, the positive influence of invaders is in most cases limited to only single species or groups of organisms, while the overall impact on ecosystems remains negative (Bartomeus et al. 2008; De Groot et al. 2007; Fenesi et al. 2015b). Moreover, the influence of 
invasive plants on ecosystems may change during the growing season, e.g. the invaders may have a neutral influence on native plants in 1 month and be competitive in the next one (De Groot et al. 2007; Fenesi et al. 2015b).

Canadian goldenrod (Solidago canadensis L.) is one of the most successful and widespread invasive plant species all over Europe (Weber 1998). This species is able to modify the ecosystem strongly, e.g. the soil characteristics (Zhang et al. 2009). In addition, it has allelopathic effects on other plant species, i.e. it releases substances that decrease the growth and survival of other plants (Abhilasha et al. 2008). The goldenrod can also limit the access of other organisms to light and water because of its height (up to $2 \mathrm{~m}$ ) and high densities (Chapuis-Lardy et al. 2006). The goldenrod cover in invaded areas reaches $90-100 \%$, so this species can produce a large amount of biomass (Moron et al. 2009). Observations have shown that on invaded plots the diversity of native plants dramatically decreases, by almost $60 \%$ (De Groot et al. 2007). Studies of the impact of the goldenrod on the native fauna have shown mostly its negative influence: a decrease in farmland bird species richness (Skórka et al. 2010), the diversity and/or abundance of butterflies, hoverflies, bumblebees, honeybees and carabid beetles (De Groot et al. 2007; Fenesi et al. 2015b; Moroń et al. 2009). However, De Groot et al. (2007) showed that in some months of the year, the influence of goldenrod on hoverflies might be positive. Therefore, it is important not to overgeneralize the impact of goldenrod on different taxa, as it depends also on time in the growing season.

Spiders are important predators among arthropods in farmland. They are generalists and limit the abundance of many insect species (a lot of which are pests), thus they are reported as providers of ecosystem services (Zhang et al. 2007). The relationship between spiders and Canadian goldenrod is well known from the literature (Cangialosi 1989; Miller 1966; Morse 1995). Spiders prefer the goldenrod as feeding habitats because of the large surface of the plants to build webs (Cangialosi 1989), resulting in increased hunting success and body weight gain (Morse 1995). Spiders from the families Araneidae, Salticidae and Clubionidae are known to use galls on the goldenrod as a moulting place (Miller 1966). However, all the studies were made in North America, in the natural range of this species. In Europe, the situation may differ, because of the different spider species, their prey species and communities, as e.g. a study on carabid beetles conducted in Europe has shown a decrease in the abundance of these predators, because of the lack of prey insects (De Groot et al. 2007). Another important issue is that all the studies were conducted during summer or autumn, i.e. the season when goldenrods flower (Werner et al. 1980). Flowers are attractive for many insect species and might influence spider abundance. There is no study on the influence of $S$. canadensis on ecosystems in spring, when last-year stems are dry, but still provide potential habitats for arthropods. In this study, we show the relationship between goldenrod dry stems and spider community in farmland. We tested the hypothesis that last-year, dry stems of $S$. canadensis are better habitats for spiders than native plants (tall grasses), because of an increase in hunting success. It might be a rare example of a positive influence of invasive species on the native fauna and ecosystem services. To our best knowledge, it is also the first study that shows the impact of an invasive plant outside the growing season.

\section{Materials and methods}

\section{Study area}

The study was carried out in May 2015 in the Barycz Valley (SW Poland). The study area is an extensive farmland with a mosaic of arable fields, meadows, small woodlots and scattered trees and shrubs of various ages, dominated by white willow (Salix fragilis L.), silver birch (Betula pendula Roth), black poplar (Populus nigra L.) and pine (Pinus sylvestris L.). It includes both dry sandy and moist sites (for details, see Ekner-Grzyb et al., 2013). Observations were made on 13 meadows at two localities, distant about $5 \mathrm{~km}$ from each other: Granowiec $\left(51^{\circ} 29^{\prime} 58^{\prime \prime} \mathrm{N}, 17^{\circ} 38^{\prime} 17^{\prime \prime} \mathrm{E}\right)$ and Szklarka $\left(51^{\circ} 30^{\prime} 17 \mathrm{~N}\right.$, $17^{\circ} 34^{\prime} 28^{\prime \prime} \mathrm{E}$ ). Out of the 13 sites, seven meadows were covered by Canadian goldenrod (four at Szklarka, three at Granowiec) and six were not (three in both localities). On the sites invaded by Solidago canadensis, there were no other tall plants, while on the non-invaded sites, only the native Poaceae (grasses) were growing. The invaded and non-invaded sites were very close and bordered one another in both localities. The size of the patch covered by goldenrod was $1500 \mathrm{~m}^{2}$ at Szklarka and $150 \mathrm{~m}^{2}$ at Granowiec. Outside these patches, all tall $(>50 \mathrm{~cm})$ plants were native grasses.

\section{Study procedures}

On each site, a $1-\mathrm{m}^{2}$ square plot was randomly chosen, and entire tall plants $(>50 \mathrm{~cm})$ were cut. Next, all the collected tall plants were separately put into plastic bags. After transfer to the laboratory, the collected plants were examined using a stereomicroscope. The presence of spider nets (i.e. any spider threads), spiders and prey items in nets were recorded. The number of prey items and spiders identified to family level was counted. All the found spiders were alive. 


\section{Statistical analysis}

Statistical analyses were made using SPSS version 21 software. Numbers of spiders, spider nets and prey items on plants were dependent variables, while type of plants (goldenrod vs. grasses) was independent variables. The distribution of data on numbers of plants, spiders and prey items was not normal, so the data were logarithmically transformed. All the tests (Student's $t$ test, $\chi^{2}$ test with Yates' correction, Wald test) were parametric and twotailed.

\section{Results}

During the study, from the 13 sites, 323 plant samples were collected (150 native plants and 173 goldenrod plants). On the invaded meadows, the mean density of Solidago canadensis individuals $/ \mathrm{m}^{2}$ was 24.7 (95 \% CL 15.9-33.6), while on meadows without the goldenrod the mean density of tall grasses was 25.0 (95\% CL 2.8-47.2). There was no significant correlation between density of native and invasive plants ( $t$ test, $t=-0.491$, df $=11, p=0.63$ ). Spider webs were much more frequent on the goldenrod than on grasses ( $25 \%$ on native grasses, $95 \%$ CL 18-32; vs. $94 \%$ on goldenrod, $95 \%$ CL $90-97$ ), and the difference between spider web presence on plants was significant $\left(\chi^{2}\right.$ with Yates' correction $\left.=40.33, p<0.0001\right)$. Therefore, there was also a higher probability of spider and prey occurrence on the goldenrod (for spiders, logistic regression $B=2.251 \pm 0.328$, Wald $=47.171, p<0.001$; for prey, $B=3.536 \pm 0.316, p<0.001)$. Moreover, on 17 goldenrod stems, more than one spider was present $(2$ spiders on 15 steams, 3 on 1 , and 4 on 1), which never happened on grasses. Our results show that the total numbers of spiders and prey items per $\mathrm{m}^{2}$ were also higher on invaded plots (for spiders, 14.6, $95 \%$ CL 5.3-23.9; for prey, 155.3, $95 \%$ CL 75.4-235.2) than on non-invaded ones (for spiders, 2.2, $95 \%$ CL 0.1-4.4; for prey, 13.8, $95 \%$ CL 4.4-32.1). The differences in numbers of spiders and prey items per $\mathrm{m}^{2}$ were significant (for spiders, $t=-3.320$, df $=10, p<0.01$; for prey, $t=-5.324$, $\mathrm{df}=11, p<0.001$, see Fig. 1). Also numbers of prey items per spider (all families) were higher on invaded plots than on non-invaded ones (invaded, 6.5, $95 \%$ CL 5.4-7.6; non-invaded $1.4,95 \%$ CL $0.5-2.3 ; t$ test, $t=3.469$, $\mathrm{df}=84, p<0.001)$. When only the Araneidae were analysed, differences between plots were also statistically significant ( $t$ test, $t=2.233$, df $=41, p<0.05$ ).

Identification of the collected spiders shows that they belong to four families: the Thomisidae, Salticidae, Araneidae and Theridiidae. On native plants, only the Thomisidae and Araneidae were observed, while on
Canadian goldenrod, the spiders belong to all four families (Table 1). There was a significant difference in number of spider families on the goldenrod versus native plants $\left(\chi^{2}=13.56, \mathrm{df}=3, p<0.01\right)$.

\section{Discussion}

Results of this study fully support the hypothesis that lastyear, dry stems of Solidago canadensis are more preferred habitats for spiders than native plants (tall grasses). On the sites non-invaded by Canadian goldenrod, on average only 2.2 spiders $/ \mathrm{m}^{2}$ were observed, compared to 14.6 spiders $/ \mathrm{m}^{2}$ (nearly sevenfold more) on invaded plots. The abundance of spiders is not a result of a higher density of tall plants on plots, as there were no significant differences in their density. On non-invaded plots, on average 25.0 tall plants/ $\mathrm{m}^{2}$ were found, whereas on invaded plots, on average 24.7 goldenrod plants $/ \mathrm{m}^{2}$ were noticed. There was also a higher probability of finding a spider or its web on the goldenrod than on grasses. In the literature, the goldenrod is well known as spider habitat, but all the studies were conducted in the native range of $S$. canadensis and during the flowering season (Cangialosi 1989; Miller 1966; Morse 1995). In this study, spiders belonging to four families were noticed: the Thomisidae, Salticidae, Araneidae and Theridiidae. All these spider families were represented on flowering Canadian goldenrod in its native area (Greco and Kevan 1999; Miller 1966; Morse 1992). There were differences between spider communities on invaded and noninvaded plots. On the sites covered by the goldenrod, we found members of all the mentioned spider families. However, the Thomisidae and Salticidae were rare (one and six individuals, respectively). Most of the recorded spiders were members of the Araneidae (48 individuals) and Theridiidae (44 individuals). The spider community on the sites non-invaded by goldenrod was poorer. It is interesting that no theridiidae spiders were observed on native plants, but they were common on nearby plots covered by $S$. canadensis. Spiders of this family are known to build large webs (Benjamin and Zschokke 2003), so it is possible that these spiders avoid thin plants, like grasses, as foraging habitats. The low numbers of the Thomisidae and Salticidae were not surprising, as these spiders are ambush predators and they do not build webs, but they forage on lower plants, near the ground (Jackson and Pollard 1996; Morse 1984).

Our results suggest also a higher probability of prey occurrence in webs on goldenrod plants than on native vegetation. On invaded plots, we recorded 155.3 prey items $/ \mathrm{m}^{2}$ versus 13.8 prey items $/ \mathrm{m}^{2}$ on non-invaded plots. This difference in prey abundance per plot is higher than the difference in spider abundance. The reason of this 

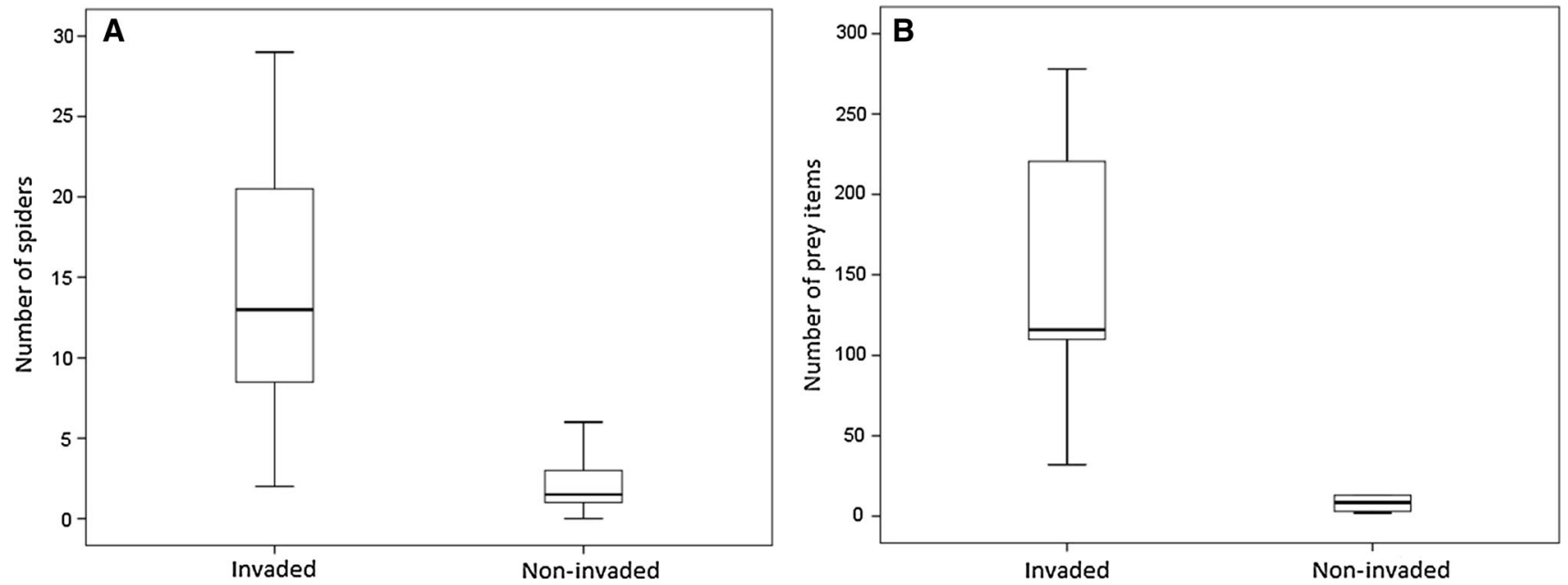

Fig. 1 Number of spiders (a) and prey items in webs (b) per $\mathrm{m}^{2}$ on plots invaded and non-invaded by Solidago canadensis (significance of differences: $p<0.01$ for $\mathbf{a}$ and $p<0.001$ for $\mathbf{b}$ )

Table 1 Numbers of spiders of four families found on Solidago canadensis and native grasses

\begin{tabular}{lcc}
\hline Family & S. canadensis & Native grasses \\
\hline Thomisidae & 1 & 1 \\
Salticidae & 6 & 0 \\
Araneidae & 48 & 12 \\
\hline
\end{tabular}

There are significant differences in number spiders families on these plants $\left(\chi^{2}=13.56, \mathrm{df}=3, p<0.01\right)$

phenomenon is probably the larger surface to build the web on S. canadensis than on grasses (Cangialosi 1989). The study was conducted in spring on non-flowering plants, and thanks to that there is no effect of flowers as attractants for insects (Fiedler and Landis 2007). Thus, we suppose that the main reason for the higher hunting success and hence spider abundance is the structure of the plants. It is known that at least one of the other arthropod predators-the bug Phymata americana-uses goldenrod plants as foraging area, but the bug is an ambush predator and probably gains from goldenrod attractiveness for prey insects (Greco and Kevan 1995). The goldenrod invasion in farmland increases spider abundance and it might be a positive aspect for ecosystem services (Zhang et al. 2007). Spiders are effective pest predators and are proposed as a solution in biological pest control (Marc and Canard 1997; Riechert and Lockley 1984; Sunderland and Samu 2000).

In conclusion, the presented study has shown that $S$. canadensis invasion on natural meadows provides a favourable habitat for two spider families. The most probable reason for this phenomenon is the larger surface for web building on goldenrod than on native plants. To our knowledge, this is the first report that the invasive Canadian goldenrod can affect animal communities during spring, when its stems are dry. This finding is also a rare example of positive impact of an invasive plant on a native species community. However, there is also a probability that the areas invaded by goldenrod are ecological traps for spiders. The presented study cannot answer this question because of the lack of data about spider fitness, survival and reproduction. Further studies in this field are needed to determine the influence of goldenrod on the condition of spider populations.

Acknowledgments This work was supported by a grant for young scientists no. 507.511.29 from the Poznan University of Life Sciences.

Funding The grant for young scientists no. 507.511.29 from the Poznan University of Life Sciences (project manager: Krzysztof Dudek) provided funds for field visits (travel and accommodation).

\section{Compliance with ethical standards}

Conflict of interest We declare that there is no conflict of interest. All of the authors agree to submission of this paper. The manuscript has not been previously published in any language anywhere and it is not under simultaneous consideration or in press by another journal.

Open Access This article is distributed under the terms of the Creative Commons Attribution 4.0 International License (http://creative commons.org/licenses/by/4.0/), which permits unrestricted use, distribution, and reproduction in any medium, provided you give appropriate credit to the original author(s) and the source, provide a link to the Creative Commons license, and indicate if changes were made.

\section{References}

Abhilasha D, Quintana N, Vivanco J et al (2008) Do allelopathic compounds in invasive Solidago canadensis sl restrain the native European flora? J Ecol 96:993-1001 
Bartomeus I, Vilà M, Santamaría L (2008) Contrasting effects of invasive plants in plant-pollinator networks. Oecologia 155:761-770

Benjamin SP, Zschokke S (2003) Webs of theridiidae spiders: construction, structure and evolution. Biol J Linn Soc 78:293-305

Cangialosi KR (1989) Differences in web-spider communities associated with three old-field communities in southwest Ohio. Ohio J Sci 89:88-92

Chapuis-Lardy L, Vanderhoeven S, Dassonville N et al (2006) Effect of the exotic invasive plant Solidago gigantea on soil phosphorus status. Biol Fertil Soils 42:481-489

Chittka L, Schürkens S (2001) Successful invasion of a floral market. Nature 411:653

De Groot M, Kleijn D, Jogan N (2007) Species groups occupying different trophic levels respond differently to the invasion of semi-natural vegetation by Solidago canadensis. Biol Conserv 136:612-617

Fenesi A, Geréd J, Meiners SJ et al (2015a) Does disturbance enhance the competitive effect of the invasive Solidago canadensis on the performance of two native grasses? Biol Invasions 17:3303-3315

Fenesi A, Vágási CI, Beldean M et al (2015b) Solidago canadensis impacts on native plant and pollinator communities in differentaged old fields. Basic Appl Ecol 16:335-346

Fiedler AK, Landis D (2007) Attractiveness of Michigan native plants to arthropod natural enemies and herbivores. Environ Entomol 36:751-765

Greco CF, Kevan PG (1995) Patch choice in the anthophilous ambush predator Phymata americana: improvement by switching hunting sites as part of the initial choice. Can J Zool 73:1912-1917

Greco CF, Kevan PG (1999) Polyethism in foraging in a polymorphic predator, Enoplognatha ovata (Araneae: Theridiidae): a case for balance. Can Entomol 131:259-268

Hejda M, Pyšek P, Jarošík V (2009) Impact of invasive plants on the species richness, diversity and composition of invaded communities. J Ecol 97:393-403

Jackson R, Pollard S (1996) Predatory behavior of jumping spiders. Annu Rev Entomol 41:287-308

Marc P, Canard A (1997) Maintaining spider biodiversity in agroecosystems as a tool in pest control. Agric Ecosyst Environ 62:229-235

Miller WE (1966) Spiders in old insect galls on goldenrod. Ohio J Sci 66:618-619

Moroń D, Lenda M, Skórka P et al (2009) Wild pollinator communities are negatively affected by invasion of alien goldenrods in grassland landscapes. Biol Conserv 142:1322-1332

Morse DH (1984) How crab spiders (Araneae, Thomisidae) hunt at flowers. J Arachnol 12:307-316

Morse DH (1992) Dispersal of the spiderlings of Xysticus emertoni (Araneae, Thomisidae), a litter-dwelling crab spider. J Arachnol 20:217-221

Morse DH (1995) Changes in biomass of penultimate-instar crab spiders Misumena vatia (Araneae, Thomisidae) hunting on flowers late in the summer. J Arachnol 23:85-90

Pétillon J, Ysnel F, Canard A et al (2005) Impact of an invasive plant (Elymus athericus) on the conservation value of tidal salt marshes in western France and implications for management: responses of spider populations. Biol Conserv 126:103-117

Pétillon J, Lambeets K, Montaigne W et al (2010) Habitat structure modified by an invasive grass enhances inundation withstanding in a salt-marsh wolf spider. Biol Invasions 12:3219-3226

Riechert SE, Lockley T (1984) Spiders as biological control agents. Annu Rev Entomol 29:299-320

Schirmel J, Timler L, Buchholz S (2011) Impact of the invasive moss Campylopus introflexus on carabid beetles (Coleoptera: Carabidae) and spiders (Araneae) in acidic coastal dunes at the southern Baltic Sea. Biol Invasions 13:605-620

Schirmel J, Bundschuh M, Entling MH et al (2015) Impacts of invasive plants on resident animals across ecosystems, taxa, and feeding types: a global assessment. Glob Change Biol 22:594-603

Skórka P, Lenda M, Tryjanowski P (2010) Invasive alien goldenrods negatively affect grassland bird communities in Eastern Europe. Biol Conserv 143:856-861

Sunderland K, Samu F (2000) Effects of agricultural diversification on the abundance, distribution, and pest control potential of spiders: a review. Entomol Exp Appl 95:1-13

Weber E (1998) The dynamics of plant invasions: a case study of three exotic goldenrod species (Solidago L.) in Europe. J Biogeogr 25:147-154

Werner PA, Gross RS, Bradbury IK (1980) The biology of Canadian weeds.: 45. Solidago canadensis L. Can J Plant Sci 60:1393-1409

Zhang W, Ricketts TH, Kremen C et al (2007) Ecosystem services and dis-services to agriculture. Ecol Econ 64:253-260

Zhang CB, Wang J, Qian BY et al (2009) Effects of the invader Solidago canadensis on soil properties. Appl Soil Ecol 43:163-169 